\title{
Land Use Adaptation to Climate Change: Economic Damages from Land-Falling Hurricanes in the Atlantic and Gulf States of the USA, 1900-2005
}

\author{
Asim Zia \\ Department of Community Development and Applied Economics, University of Vermont, \\ 146 University Place, Morrill 208E, Burlington, VT 05482, USA; E-Mail: Asim.Zia@uvm.edu; \\ Tel.: +1-802-656-4695; Fax: +1-802-656-4447
}

Received: 1 February 2012; in revised form: 25 April 2012 / Accepted: 25 April 2012 /

Published: 7 May 2012

\begin{abstract}
Global climate change, especially the phenomena of global warming, is expected to increase the intensity of land-falling hurricanes. Societal adaptation is needed to reduce vulnerability from increasingly intense hurricanes. This study quantifies the adaptation effects of potentially policy driven caps on housing densities and agricultural cover in coastal (and adjacent inland) areas vulnerable to hurricane damages in the Atlantic and Gulf Coastal regions of the U.S. Time series regressions, especially Prais-Winston and Autoregressive Moving Average (ARMA) models, are estimated to forecast the economic impacts of hurricanes of varying intensity, given that various patterns of land use emerge in the Atlantic and Gulf coastal states of the U.S. The Prais-Winston and ARMA models use observed time series data from 1900 to 2005 for inflation adjusted hurricane damages and socio-economic and land-use data in the coastal or inland regions where hurricanes caused those damages. The results from this study provide evidence that increases in housing density and agricultural cover cause significant rise in the de-trended inflation-adjusted damages. Further, higher intensity and frequency of land-falling hurricanes also significantly increase the economic damages. The evidence from this study implies that a medium to long term land use adaptation in the form of capping housing density and agricultural cover in the coastal (and adjacent inland) states can significantly reduce economic damages from intense hurricanes. Future studies must compare the benefits of such land use adaptation policies against the costs of development controls implied in housing density caps and agricultural land cover reductions.
\end{abstract}


Keywords: climate change; adaptation; land-use policy; economic damages; disaster management; extreme weather events; risk assessment; dynamic modeling

\section{Introduction}

The Intergovernmental Panel for Climate Change (IPCC) Fourth Assessment Report [1] established with very high confidence that anthropogenic intervention is forcing a change in the climate, such as Green House Gas (GHG) emissions at the current rate will increase the global mean temperature by $2.8 \mathrm{C}$ by the end of 21 st century. Another impact of increased GHG emissions, and subsequent global warming, is expected to be on the increased intensity of hurricanes by a factor of $8 \%$ to $16 \%$ during the 21 st century [2]. While it is generally expected that the increased intensity of hurricanes will cause higher economic and societal damage where the hurricanes would make landfalls, it is not yet known how much more damage would occur. In fact, the challenge of estimating a damage function from increased intensity of hurricanes is a controversial topic. For example, in the aftermath of hurricane Katrina and a rather destructive hurricane season in 2005, the journal Nature published an interesting debate between Pielke Jr. [3] and Emanuel [4]. Pielke Jr. [3] takes a rather strong position in arguing for a non-significant upward trend in the "normalized" damages from hurricanes during the 20th century. Based on earlier analyses [5,6], Pielke Jr. [3] argues that inflation adjusted damages from hurricanes can be de-trended by normalizing them with increases in population and wealth. More formally, it is proposed that normalization of hurricane damages should be undertaken as suggested in Equation (1):

Normalized Damage $=$ Original Damage $x$ GNP Inflation Index x FRTW Index [7] $x$ Coastal County Population Change

Equation (1) makes two major assumptions in "normalizing" the damages: First, damages from hurricanes are monotonically increasing functions of population and wealth. Second, population and wealth changes are given equal weights in normalizing the damages. It is hypothesized in this paper that both of these assumptions are not tenable and may lead to an incorrect "normalization" of damages. It is argued that normalization of damages should only be adjusted for inflation, as suggested in Equation (2):

$$
\text { Normalized Damage }=\text { Original Damage } \times \text { GNP Inflation Index }
$$

Following the normalization proposed in Equation (2), it is possible to construct statistical and structural models for testing the two assumptions made by Pielke and Landsea [5,6]. Furthermore, the revised normalization proposed in Equation (2) enables forecasting the normalized damages in the face of changing intensities of hurricanes (due to global warming as suggested by Emanuel [4]), and changing socio-economic and demographic conditions. Most importantly, it enables assessing the structural weights of not only population and wealth effects on damages rather other social and demographic effects (e.g., housing, agricultural land cover, population configuration) can also be assessed and weighted. A long term structural assessment is important from two aspects: (1) Forecasting the hurricane damages in the 21 st century if we continue with "business as usual" scenario, such as IPCC's A1 
scenario family; (2) Forecasting hurricane damages in the 21 st century if we adapt through various policy \& planning interventions and behavioral changes.

While global coastal communities will very likely be exposed to a range of socio-economic impacts from unmitigated global climate change, such as sea level rise, flash floods, and heat waves [8], this paper is limited in its scope to measuring the impact of increased intensity of hurricanes in the Atlantic and Gulf coastal regions of the U.S., as observed in the 20th century. Such assessment is aimed at establishing a baseline case of spontaneous adaptation under current Land Use and Land Cover (LULC) trends. This baseline case, in turn, could be compared with alternate scenarios of planned adaptation through policy driven changes in LULC as suggested by Kelly and Adger [9] and Adger et al. [10]. In this broader context of climate change adaptation policy development, the scope of this paper is delimited to estimating economic damage functions from increased intensity of hurricanes conditional upon LULC developments in the coastal communities and other natural variability. It is hypothesized that adaptation in the form of policy driven caps on the growth rates of housing densities and agricultural land use in the coastal areas vulnerable to hurricane damages could lead to significantly reduced damages from $8 \%$ to $16 \%$ more intense hurricanes expected to make landfall in the 21 st century. This study thus quantifies the adaptation effects of potentially policy driven caps on housing densities and agricultural cover in coastal (and adjacent inland) areas vulnerable to hurricane damages in the Atlantic and Gulf Coastal regions of the U.S. Time series regressions, especially Prais-Winston and Autoregressive Moving Average (ARMA) models, are estimated to forecast the economic impacts of hurricanes of varying intensity, given that various patterns of LULC emerge in the Atlantic and Gulf coastal states of the U.S. The Prais-Winston and ARMA models use observed time series data from 1900 to 2005 for inflation adjusted hurricane damages and socio-economic and land-use data in the coastal or inland regions where hurricanes caused those damages. Next Section 2 presents detailed information about empirical data and the research methodology. Section 3 presents results and their interpretations. Section 4 discusses the limitations and prospects of this modeling approach vis- $a$-vis other socio-economic impact assessment approaches. Section 5 presents the implications of the study findings for land-use adaptation to climate change in the broader public policy and planning context.

\section{Data and Research Methodology}

This study uses hurricane damages data for one hundred and five years (1900-2005) [11]. A portion of the same damage data from 1926-1995 has been initially analyzed by Pielke Jr. and Landsea [5]. As mentioned earlier, their analysis focused on normalizing the damages by inflation, wealth and population indices. Pielke Jr. and Landsea [5] found that the normalized damages from hurricanes have neither increasing nor decreasing trend during the 1926-1995 period. Same "normalized" data was employed by Katz [12] in a Poisson regression model to model changes in the incidence rates of landfalling hurricanes and a log normal model to predict changes in the normalized damages when hurricanes make landfalls. The authors of both of these studies, however, did not use the hurricane damage data to predict the expected damages that are conditional upon changes in the intensity of the hurricanes, as well as land-use, societal and economic changes, such as population density, housing densities, and agricultural land cover. It should be noted that the Landsea Hurricane damages data follows a heuristic of doubling insurance losses, which may not be true and thus may induce a measurement error. Due to 
non-standard data collection procedures in the first half of the 20th century, the hurricane damage data in the initial fifty to sixty years may contain higher measurement error than the latter half of the series. Further, Landsea damages data does not include fatalities, social costs, ecological costs and other indirect damages from hurricanes.

Socio-economic data about the housing and population densities of the affected areas as well as \% agricultural cover was derived from U.S. census data. Since the census data is measured on a decadal time-scale, linear interpolation method was used to derive annualized estimates for socio-economic variables of interest. SST Nino, which refers to observed Sea Surface Temperature variability at intra-decadal time-scale, is derived from a National Climate Center database. It is included in the models because Katz [12] and Pielke Jr. and Landsea [6] hypothesized that normalized damages increase in La Nina years and decrease in El Nino years.

Table 1 presents descriptive statistics of the annualized time series data from 1900 to 2005. This table shows that annual damages from hurricanes in U.S. Atlantic and Gulf coasts averaged US $\$ 2937.73$ Million, which ranged from $0 \%$ to $0.99 \%$ as a proportion of the U.S. Fixed Reproducible Tangible Wealth (FRTW). Annual damages per square mile of the affected area averaged US\$0.42 Million. On average, 1.62 hurricanes made landfall every year with an average intensity of 1.71 (on Safire Simpson (SS) Scale). Annually, 13,079.13 Square Miles of land were affected by landfalling hurricanes, which affected on average 2.46 million people. Average annual population density affected by hurricanes is about 182 persons/square mile. On average, 1.01 million houses get affected by landfalling hurricanes every year, which means average annual housing density affected by hurricanes is about 66 houses/square mile. About $31.07 \%$ of the total affected land is agricultural.

Figure 1 shows annual damages from hurricanes in 2005 US \$ Millions. This figure shows an upward trend in annualized damages. Figure 2 shows a logarithmic transformation of the annualized damages. Figure 3 plots inter-decadal variability by plotting the number of land-falling hurricanes against SST Nino. There is no clear statistically significant trend between La Nina and El Nino years in terms of increasing or decreasing frequency of land-falling hurricanes. Figure 4 shows variation in the average intensity of land-falling hurricanes vis-à-vis SST Nino, again without any significant discernable trend.

This study develops a time series forecasting model that can predict the inflation-adjusted damages at different intensities of hurricanes, while controlling for housing densities of the areas impacted by the hurricanes. Such forecasting model could potentially be used to predict the damages in the next one hundred years (2006-2106), if policy/planning interventions are employed to carry out various land-use adaptations (i.e., manipulating the trends in housing densities, population densities, and agricultural land cover at various planning thresholds). 
Table 1. Descriptive Statistics.

\begin{tabular}{|c|c|c|c|c|c|}
\hline Variable & $\mathbf{N}$ & Minimum & Maximum & Mean & $\begin{array}{l}\text { Standard } \\
\text { Deviation }\end{array}$ \\
\hline Annual Damages (2005 U.S. Million \$) & 106 & 0 & 99,150 & $2,937.73$ & $11,340.11$ \\
\hline Ln (Damages) & 80 & 14.34 & 25.32 & 19.74 & 2.35 \\
\hline $\begin{array}{l}\text { Annual Damages as \% of Fixed } \\
\text { Reproducible Tangible Wealth (\%) }\end{array}$ & 106 & 0 & 0.99 & 0.05 & 0.13 \\
\hline $\begin{array}{l}\text { Ln (Annual Damages as \% of Fixed } \\
\text { Reproducible Tangible Wealth) }\end{array}$ & 80 & -10.54 & -0.01 & -4.30 & 2.12 \\
\hline Annual Hurricane Frequency & 106 & 0 & 6 & 1.62 & 1.43 \\
\hline $\begin{array}{l}\text { Average Annual Hurricane Intensity } \\
\text { (Safire-Simpson Scale) }\end{array}$ & 106 & 0 & 4 & 1.71 & 1.20 \\
\hline Annual Affected Area (Square Miles) & 106 & 0 & 238,409 & $13,079.13$ & $34,995.14$ \\
\hline Annual Affected Population & 106 & 0 & $41,664,959$ & $2,465,596$ & $7,255,926$ \\
\hline $\begin{array}{l}\text { Annual Affected Population Density } \\
\text { (People/Sq Mile) }\end{array}$ & 80 & 2.51 & $4,604.81$ & 181.80 & 522.43 \\
\hline Annual Affected Houses & 106 & 0 & $21,742,632$ & $1,011,516$ & $3,299,449$ \\
\hline $\begin{array}{l}\text { Annual Affected Housing Density } \\
\text { (Houses/ Sq Mile) }\end{array}$ & 80 & 0.51 & $1,512.35$ & 66.01 & 174.73 \\
\hline $\begin{array}{l}\% \text { of Agricultural Land in the Affected } \\
\text { Area }(\%)\end{array}$ & 80 & 0.16 & 93.65 & 31.07 & 23.17 \\
\hline $\begin{array}{l}\text { Deviations from Sea Surface } \\
\text { Temperature (SST) }\end{array}$ & 106 & -1.9 & 2.52 & 0.06 & 0.98 \\
\hline SST Nino & 106 & -1 & 1 & 0.01 & 0.82 \\
\hline Year & 106 & 1,900 & 2,005 & $1,952.5$ & 30.74 \\
\hline
\end{tabular}

Figure 1. Direct damages from hurricanes in the Atlantic and Gulf coasts.

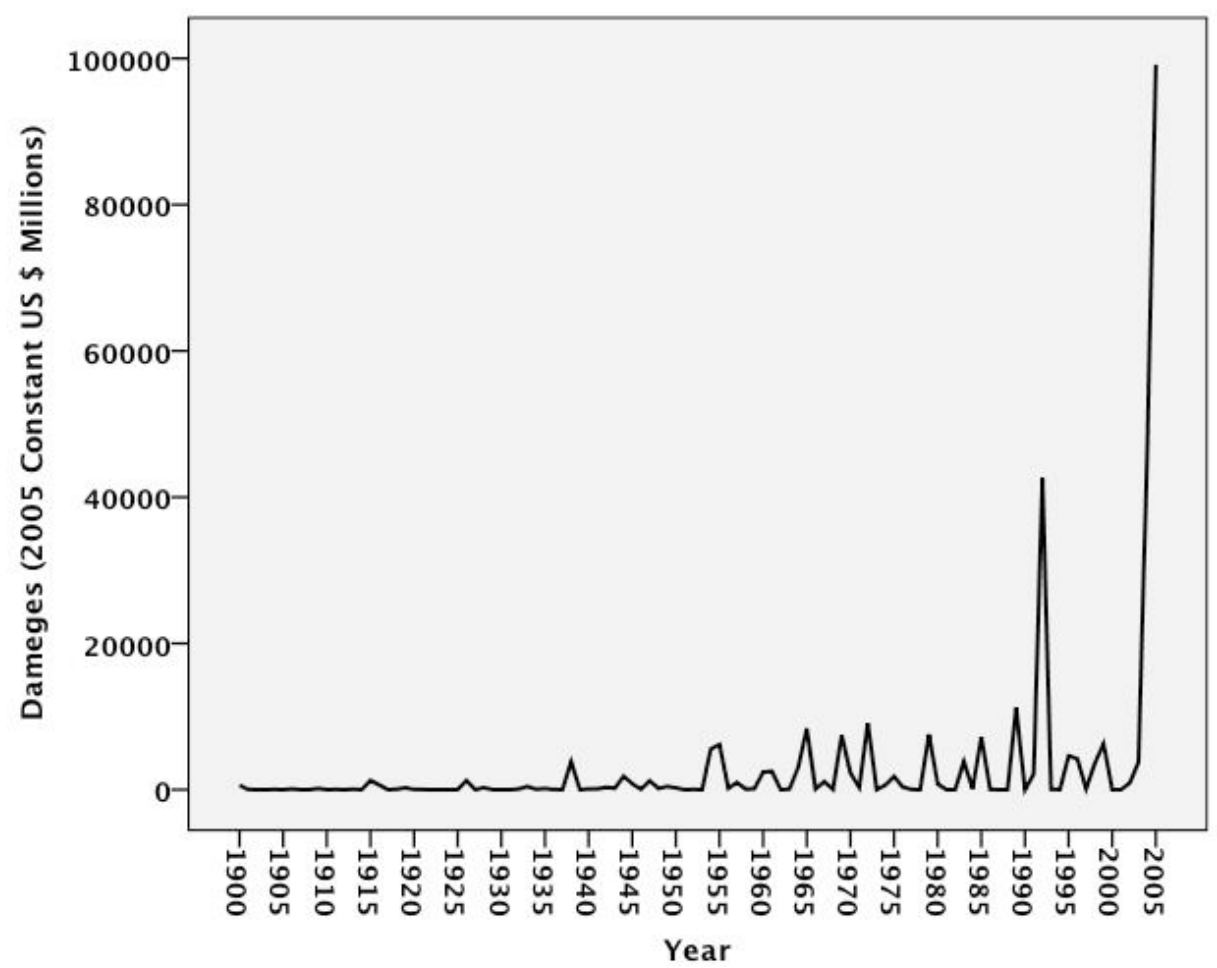


Figure 2. Log of direct damages from hurricanes in the Atlantic and Gulf coasts.

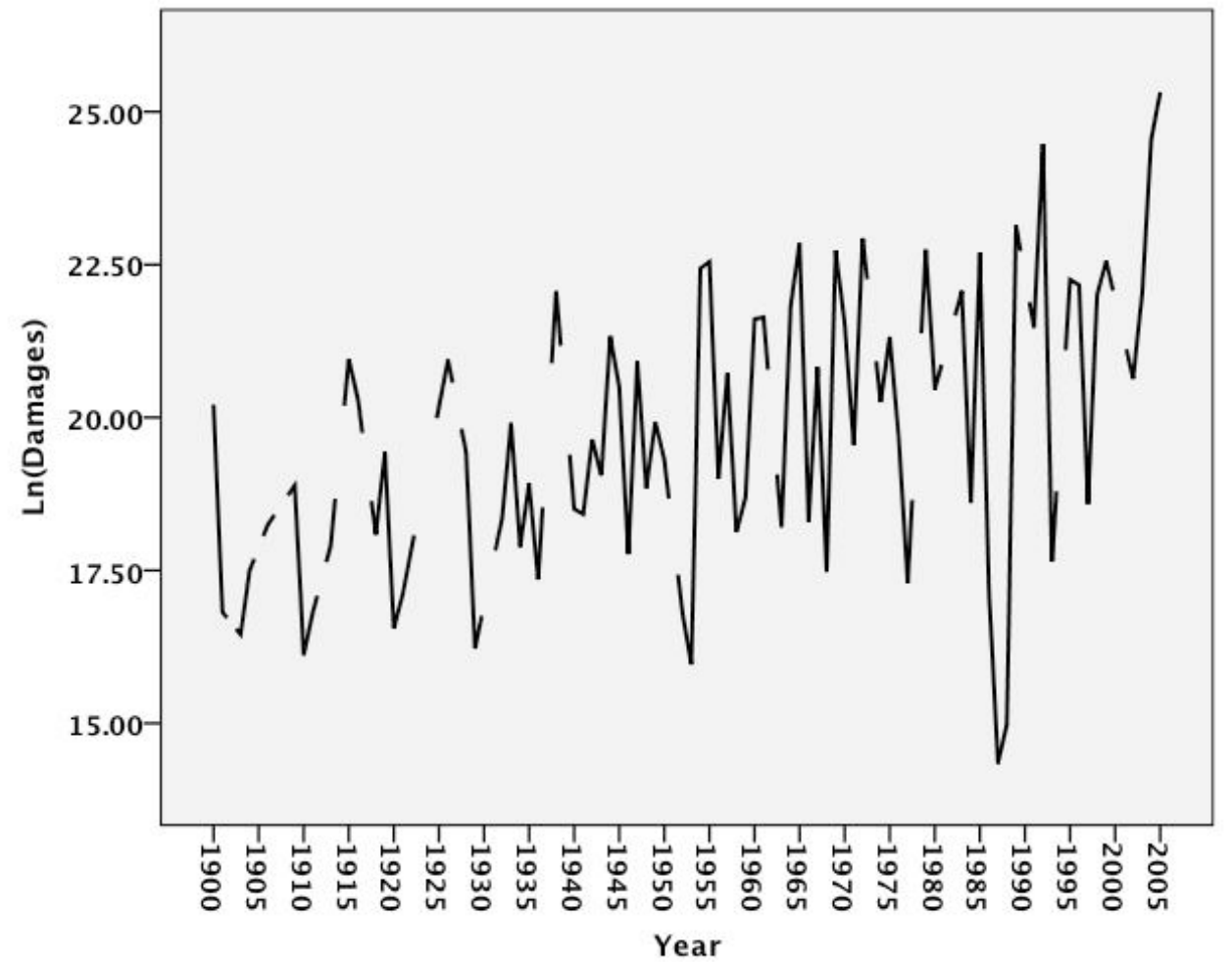

Figure 3. Inter-decadal variability of hurricane activity.

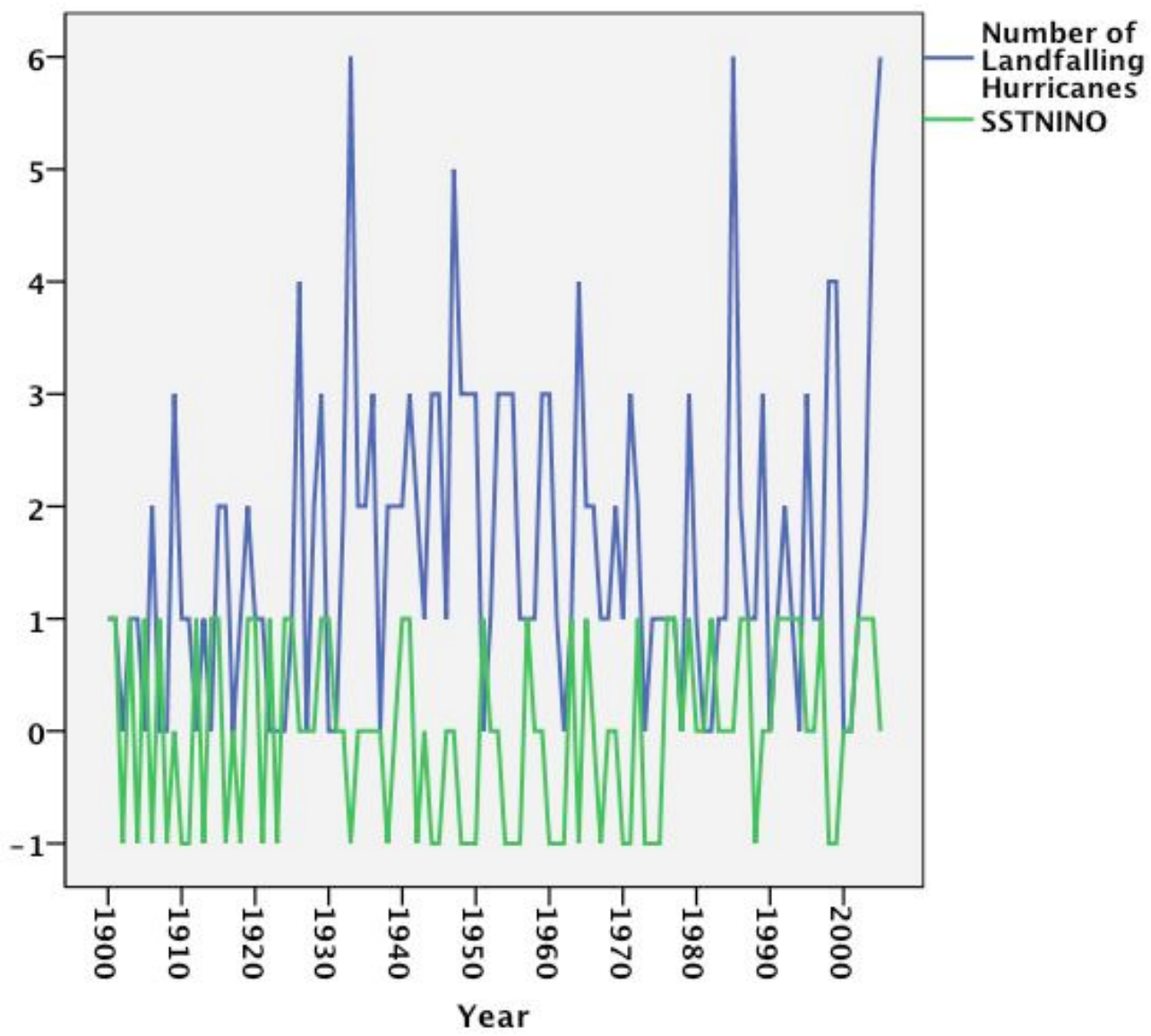


Figure 4. Variation in hurricane intensity.

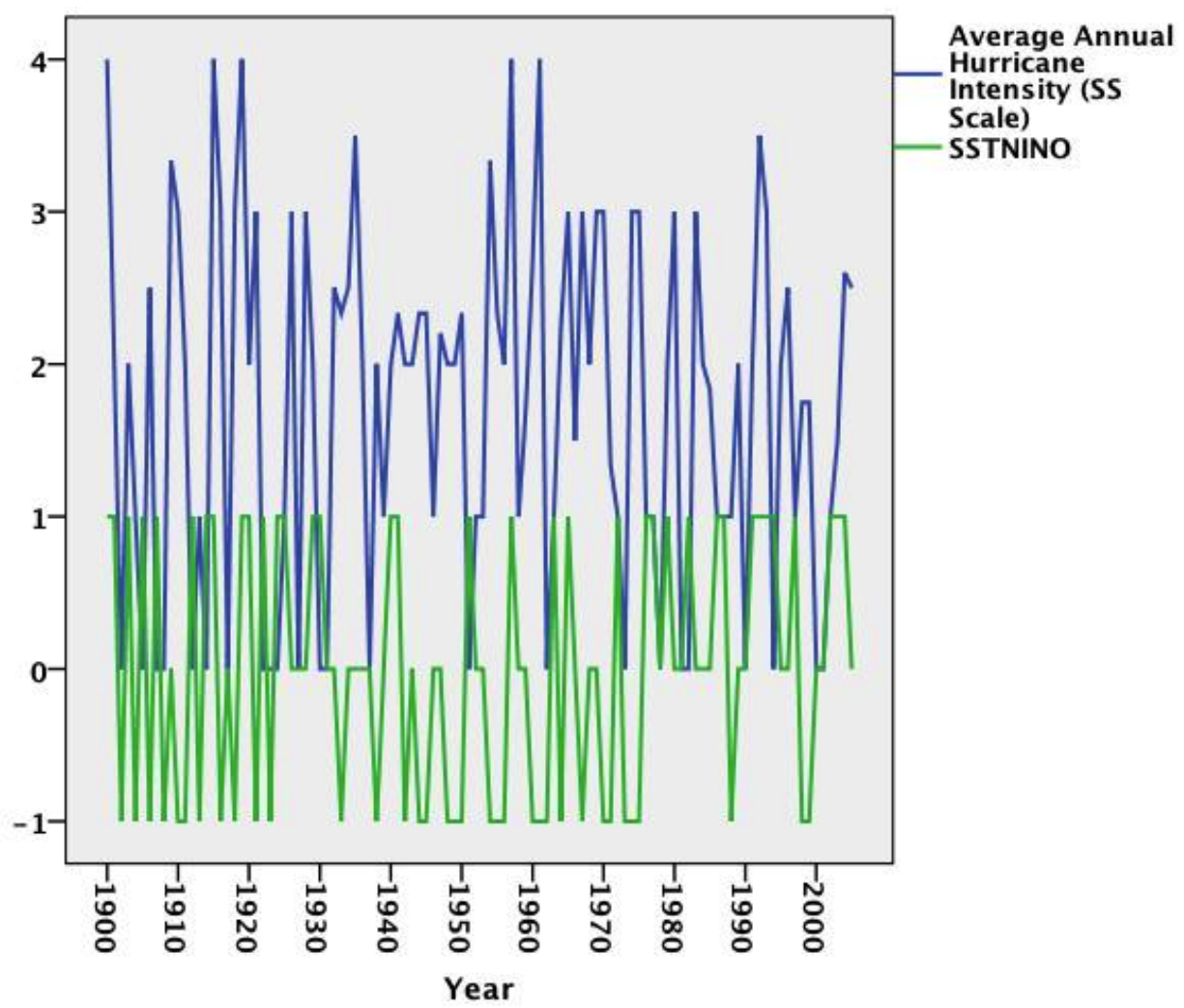

The simplest time series forecasting model uses inflation-adjusted damages (D) for a year ( $t$ ) as the dependent variable. The dependent variable could also be normalized through a measure of inflationadjusted damages as a proportion of GDP or as a proportion of FRTW. FRTW is preferred here because it only contains fixed assets, while GDP contains both fixed and liquid assets. It is hypothesized that the following predictors affect the changes in inflation-adjusted hurricane damages: (1) Average intensity of land-falling hurricanes for a year ( $\mathrm{t}$ ), measured on a Saffire-Simpson scale, $\left(\mathrm{X}_{1}\right)$; (2) Annual frequency of land-falling hurricanes $\left(\mathrm{X}_{2}\right)$; (3) Fixed Reproducible Tangible Wealth $\left(\mathrm{X}_{3}\right)$; (4) Area-weighted housing density affected by the hurricane path and their squared and cubed values $\left(\mathrm{X}_{4}\right.$ to $\left.\mathrm{X}_{6}\right)$; (5) \% of Agricultural land cover $\left(\mathrm{X}_{7}\right)$; (6) SST El Nino $\left(\mathrm{X}_{8}\right)$ and (7) Time variable measured in years $\left(\mathrm{X}_{9}\right)$. When the dependent variable is normalized by FRTW, the FRTW is dropped from the list of independent variables.

The simplest form of the model was initially specified as an OLS model, as shown in Equation (3):

$$
\mathrm{D}_{\mathrm{t}}=\sum_{\mathrm{r}=1}^{9} \beta_{\mathrm{rt}} \mathrm{X}_{\mathrm{rt}}+\varepsilon_{\mathrm{t}}
$$

Various statistical tests were employed to detect autocorrelation and heteroskedasticity for estimating the $\beta_{\mathrm{r}}$. Tables 2 and 3 in the results section provide a summary of these statistical test results. Model 1 in Table 2, for example, is an OLS model that predicts inflation-adjusted damages. Similarly, Model 5 in Table 3 is also an OLS model that predicts inflation-adjusted damages normalized by FRTW. Model 1 produced a Durbin-Watson d-statistic of 1.0324, which led to a rejection of null hypothesis of no autocorrelation [13] and acceptance of an alternative hypothesis of positive autocorrelation. Similar evidence for positive autocorrelation is observed for model 5 that predicts normalized damages. 
In addition to autocorrelation, the OLS models also manifested evidence of heteroskedasticity. Breusch-Pagan/Cook-Weisberg test was implemented to test for the null hypothesis of no heteroskedasticity in OLS models 1 and 5. This null hypothesis was rejected for both the OLS models ( $\mathrm{P}>\mathrm{chi} 2=0.0000)$. After testing for various functional forms, a logarithmic transformation of the dependent variable successfully minimized heteroskedasticity, which led to log-linear functional forms of Model 2 (Table 2) and Model 6 (Table 3). While log-linear models minimized heteroskedaskticity $(\mathrm{P}>\operatorname{chi} 2=0.0165$ for Model 3 and $\mathrm{P}>\operatorname{chi} 2=0.1788$ for Model 6$)$, the null hypothesis of no temporal autocorrelation could only be barely rejected (d-statistic of 1.3290 for Model 2 and 1.2462 for Model 6). To account for temporal autocorrelation, both Prais-Winston and ARMA modeling approaches are used by specifying auto-regression, moving average and differencing orders for stationarizing the time series. Prais-Winston regression models are special cases of generalized ARMA models that assume first order auto-regression on residual terms and adjust the regression coefficients through transforming the d-statistic. The ARMA model, as shown in Equations (4) and (5), is a more generalized approach to predict the log of damages conditional upon hurricane intensity trends, and trends in housing densities and agricultural land cover in the south eastern USA. Model 3 in Table 2 and Model 7 in Table 3 are Prais-Winston regression models to respectively predict inflation-adjusted and normalized damages. The transformed d-statistic in Prais-Winston regression models shows that the estimated coefficients in these models do not present any evidence of first-order autocorrelation. The evidence for higher order autocorrelation and moving average is tested in ARMA specifications to predict inflation-adjusted damages in Model 4 and inflation-adjusted damages as a proportion of FRTW in Model 8. While there is evidence for higher-order autocorrelation, the direction and significance of estimated coefficient values in Prais-Winston and ARMA regression models are robust and consistent.

Table 2. Estimated Models Predicting Economic Damages from Land-falling Hurricanes in the Atlantic and Gulf Coasts of the U.S., 1900-2005.

\begin{tabular}{lcccc}
\hline Variable & $\begin{array}{c}\text { OLS Model 1 } \\
\text { Predicting } \\
\text { Damages }\end{array}$ & $\begin{array}{c}\text { Loglinear } \\
\text { Model 2 } \\
\text { Predicting } \\
\text { (2005 U.S. Million \$) }\end{array}$ & $\begin{array}{c}\text { Prais-Winston } \\
\text { Model 3 }\end{array}$ & $\begin{array}{c}\text { ARMA (5,1,5) } \\
\text { Predicting } \\
\text { Model 4 } \\
\text { Predicting }\end{array}$ \\
\hline Year & $-246.2259^{* *}$ & 0.0013 & 0.0001 & Dropped \\
& $(117.6930)$ & $(0.0147)$ & $(0.0187)$ & \\
Average Annual Hurricane & $2,885.8720 * *$ & $1.3166^{* * *}$ & $1.3018 * * *$ & $1.6768^{* * *}$ \\
Intensity (Safire-Simpson Scale) & $(1,430.2020)$ & $(0.1795)$ & $(0.1805)$ & $(0.1851)$ \\
Annual Affected Housing & 50.2466 & $0.0277 * * *$ & $0.0268 * * *$ & $0.0023^{*}$ \\
Density (Houses/ Square Mile) & $(60.9161)$ & $(0.0076)$ & $(0.0073)$ & $(0.0012)$ \\
Annual Affected Housing & -0.1473 & $-0.00005^{* *}$ & $-0.00005 * *$ & Dropped \\
Density Squared & $(0.1961)$ & $(0.00002)$ & $(0.00002)$ & \\
Annual Affected Housing & 0.00007 & $2.77 \mathrm{e}-008^{* *}$ & $2.76 \mathrm{e}-08 * *$ & Dropped \\
Density Cubed & $(0.0001)$ & $(1.33 \mathrm{e}-08)$ & $(1.27 \mathrm{e}-08)$ & \\
\hline
\end{tabular}


Table 2. Cont.

\begin{tabular}{|c|c|c|c|c|}
\hline Variable & $\begin{array}{c}\text { OLS Model 1 } \\
\text { Predicting } \\
\text { Damages } \\
\text { (2005 U.S. Million \$) }\end{array}$ & $\begin{array}{c}\text { Loglinear } \\
\text { Model } 2 \\
\text { Predicting } \\
\text { Ln(Damages) } \\
\end{array}$ & $\begin{array}{c}\text { Prais-Winston } \\
\text { Model } 3 \\
\text { Predicting } \\
\text { Ln(Damages) } \\
\end{array}$ & $\begin{array}{c}\text { ARMA }(5,1,5) \\
\text { Model 4 } \\
\text { Predicting } \\
\text { Ln(Damages) } \\
\end{array}$ \\
\hline$\%$ of Agricultural Land in the & 21.7046 & $0.0189 * *$ & $0.0151 * *$ & $0.0229 * * *$ \\
\hline Affected Area & $(55.0235)$ & $(0.0069)$ & $(0.0068)$ & $(.0068)$ \\
\hline SST Nino & $\begin{array}{c}771.0973 \\
(1,519.7360)\end{array}$ & $\begin{array}{l}-0.1640 \\
(0.1907)\end{array}$ & $\begin{array}{l}-0.1507 \\
(0.1870)\end{array}$ & $\begin{array}{c}0.1572 \\
(0.2173)\end{array}$ \\
\hline Fixed Reproducible Tangible & $4.5842 * * *$ & $0.0002 *$ & 0.0003 & -0.0013 \\
\hline Wealth (2005 US \$ Billions) & $(1.2851)$ & $(0.0001)$ & $(0.0002)$ & $(0.0016)$ \\
\hline Constant & $\begin{array}{l}452,702.3000 * * \\
(225,767.7000)\end{array}$ & $\begin{array}{c}10.3225 \\
(28.3424)\end{array}$ & $\begin{array}{c}12.8121 \\
(36.0164)\end{array}$ & $\begin{array}{c}0.1090 \\
(0.1638)\end{array}$ \\
\hline $\operatorname{AR}(1)$ & N/A & $\mathrm{N} / \mathrm{A}$ & 0.3607 & $-1.9835 * * *$ \\
\hline $\operatorname{AR}(2)$ & N/A & N/A & N/A & $-2.3611 * * *$ \\
\hline AR (3) & N/A & N/A & N/A & $-1.4897 * *$ \\
\hline AR (4) & N/A & N/A & N/A & -0.4514 \\
\hline $\operatorname{AR}(5)$ & N/A & N/A & N/A & 0.2234 \\
\hline MA (1) & N/A & $\mathrm{N} / \mathrm{A}$ & $\mathrm{N} / \mathrm{A}$ & 1.0750 \\
\hline MA (2) & N/A & N/A & N/A & 0.6469 \\
\hline MA (3) & N/A & N/A & N/A & $-0.6469 * *$ \\
\hline MA (4) & N/A & N/A & N/A & -1.0750 \\
\hline MA (5) & N/A & $\mathrm{N} / \mathrm{A}$ & $\mathrm{N} / \mathrm{A}$ & $-1.0000 * * *$ \\
\hline Sigma & N/A & N/A & N/A & $1.0202 * * *$ \\
\hline $\mathrm{R}^{2}$ & 0.4378 & 0.7318 & 0.8715 & N/A \\
\hline F-test or Wald-test score & $\begin{array}{c}6.0600 * * * \\
\mathrm{~F}(9,70)\end{array}$ & $\begin{array}{c}21.22 * * * \\
\mathrm{~F}(9,70)\end{array}$ & $\begin{array}{c}52.76 * * * \\
\mathrm{~F}(9,70)\end{array}$ & $\begin{array}{c}7,229 \cdot 2700 * * * \\
\mathrm{~W}(9,60)\end{array}$ \\
\hline Durbin-Watson d-statistic & $\begin{array}{c}1.0324 \\
(10,80)\end{array}$ & $\begin{array}{l}1.3290 \\
(10,80)\end{array}$ & $\begin{array}{l}1.6921 \\
(10,80)\end{array}$ & N/A \\
\hline $\begin{array}{l}\text { Breusch-Pagan/Cook-Weisberg } \\
\text { test for heteroskedasticity }\end{array}$ & $\begin{aligned} \mathrm{Chi}^{2} & =248.0900 \\
(\mathrm{P} & =0.0000)\end{aligned}$ & $\begin{array}{l}\mathrm{Chi}^{2}=1.8100 \\
(\mathrm{P}=0.1788)\end{array}$ & N/A & N/A \\
\hline
\end{tabular}

$*$ shows significance at 0.01 level; $* *$ shows significance at 0.05 level and ${ }^{* * *}$ shows significance at 0.001 level. Numbers in brackets show standard errors. F-test or Wald-test statistic shows joint significance for all variables. N/A stands for Not Applicable. 
Table 3. Estimated Models Predicting Economic Damages as a \% Proportion of Fixed Reproducible Tangible Wealth (FRTW) from Land-falling Hurricanes.

\begin{tabular}{|c|c|c|c|c|}
\hline Variable & $\begin{array}{c}\text { OLS Model } 5 \\
\text { Predicting } \\
\text { Damages/FRTW } \\
(\%)\end{array}$ & $\begin{array}{c}\text { Loglinear Model } \\
6 \text { Predicting } \\
\text { Ln(Damages/ } \\
\text { FRTW) }\end{array}$ & $\begin{array}{c}\text { Prais-Winston } \\
\text { Model } 7 \\
\text { Predicting } \\
\text { Ln(Damages/ } \\
\text { FRTW) }\end{array}$ & $\begin{array}{c}\text { ARMA }(5,1,5) \\
\text { Model 8 } \\
\text { Predicting } \\
\text { Ln(Damages/ } \\
\text { FRTW) }\end{array}$ \\
\hline Year & $\begin{array}{c}0.0006 \\
(0.0006)\end{array}$ & $\begin{array}{c}0.0007 \\
(0.0068)\end{array}$ & $\begin{array}{c}-0.00002 \\
(0.0080)\end{array}$ & Dropped \\
\hline $\begin{array}{l}\text { Average Annual Hurricane } \\
\text { Intensity (Safire-Simpson }\end{array}$ & $\begin{array}{c}0.0496 * * \\
(0.0163)\end{array}$ & $\begin{array}{c}1.3142 * * * \\
(0.1821)\end{array}$ & $\begin{array}{c}1.3065 * * * \\
(0.1813)\end{array}$ & $\begin{array}{l}1.6710 * * * \\
(0.1804)\end{array}$ \\
\hline \multicolumn{5}{|l|}{ Scale) } \\
\hline Annual Affected Housing & $0.0015 * *$ & $0.0270 * * *$ & $0.0261 * * *$ & $0.0023 *$ \\
\hline Density (Houses/ Square Mile) & $(0.0006)$ & $(0.0077)$ & $(0.0072)$ & $(0.0012)$ \\
\hline Annual Affected Housing & $-4.08 \mathrm{e}-06 *$ & $-0.00005 * *$ & $-0.00005 * *$ & Dropped \\
\hline Density Squared & $(2.23 \mathrm{e}-06)$ & $(0.00002)$ & $(0.00002)$ & \\
\hline Annual Affected Housing & $2.3 \mathrm{e}-09 *$ & $2.63 \mathrm{e}-08 *$ & $2.65 \mathrm{e}-08 * *$ & Dropped \\
\hline Density Cubed & $\left(1.21 \mathrm{e}^{-09)}\right.$ & $\left(1.35 \mathrm{e}^{-08)}\right.$ & $(1.27 \mathrm{e}-08)$ & \\
\hline Average Annual Hurricane & $0.0386 * * *$ & $0.5785 * * *$ & $0.5909 * * *$ & $0.6979 * * *$ \\
\hline Frequency & $(0.0110)$ & $(0.1233)$ & $(0.1222)$ & $(0.1425)$ \\
\hline$\%$ of Agricultural Land in the & -0.0003 & $0.0167 * *$ & $0.0136 * *$ & $0.0224 * *$ \\
\hline Affected Area & $(0.0006)$ & $(0.0068)$ & $(0.0067)$ & $(0.0071)$ \\
\hline SST Nino & 0.0209 & -0.1040 & -0.1212 & 0.1173 \\
\hline & $(0.0168)$ & $(0.1882)$ & $(0.1855)$ & $(0.2181)$ \\
\hline Constant & $\begin{array}{l}-1.4776 \\
(1.1979)\end{array}$ & $\begin{array}{l}-11.5060 \\
(13.3742)\end{array}$ & $\begin{array}{l}-9.7455 \\
(15.7553)\end{array}$ & $\begin{array}{l}-0.0318 \\
(0.0660)\end{array}$ \\
\hline $\operatorname{AR}(1)$ & N/A & $\mathrm{N} / \mathrm{A}$ & 0.3954 & $-1.9573 * * *$ \\
\hline $\mathrm{AR}(2)$ & $\mathrm{N} / \mathrm{A}$ & N/A & $\mathrm{N} / \mathrm{A}$ & $-2.3032 * * *$ \\
\hline AR (3) & $\mathrm{N} / \mathrm{A}$ & $\mathrm{N} / \mathrm{A}$ & N/A & $-1.4156 * *$ \\
\hline AR (4) & N/A & N/A & N/A & -0.3951 \\
\hline $\mathrm{AR}(5)$ & N/A & $\mathrm{N} / \mathrm{A}$ & $\mathrm{N} / \mathrm{A}$ & 0.2503 \\
\hline MA (1) & $\mathrm{N} / \mathrm{A}$ & $\mathrm{N} / \mathrm{A}$ & $\mathrm{N} / \mathrm{A}$ & 1.0865 \\
\hline MA (2) & N/A & N/A & N/A & 0.6467 \\
\hline MA (3) & $\mathrm{N} / \mathrm{A}$ & $\mathrm{N} / \mathrm{A}$ & $\mathrm{N} / \mathrm{A}$ & $-0.6467 * *$ \\
\hline MA (4) & $\mathrm{N} / \mathrm{A}$ & $\mathrm{N} / \mathrm{A}$ & $\mathrm{N} / \mathrm{A}$ & -1.0865 \\
\hline MA (5) & N/A & N/A & N/A & $-1.0000 * *$ \\
\hline Sigma & N/A & $\mathrm{N} / \mathrm{A}$ & $\mathrm{N} / \mathrm{A}$ & $1.0431 * * *$ \\
\hline $\mathrm{R}^{2}$ & 0.4084 & 0.6550 & 0.6791 & N/A \\
\hline F-test or Wald-test score & $6.1300 * * *$ & $16.85 * * *$ & $18.78 * * *$ & $8,172.2600 * * *$ \\
\hline & $\mathrm{F}(8,71)$ & $\mathrm{F}(8,71)$ & $\mathrm{F}(8,71)$ & $\mathrm{W}(6,60)$ \\
\hline Durbin-Watson d-statistic & $\begin{array}{l}1.1380 \\
(9,80)\end{array}$ & $\begin{array}{l}1.2462 \\
(9,80)\end{array}$ & $\begin{array}{l}1.6746 \\
(9,80)\end{array}$ & N/A \\
\hline $\begin{array}{l}\text { Breusch-Pagan/Cook-Weisberg } \\
\text { test for heteroskedasticity }\end{array}$ & $\begin{aligned} \mathrm{Chi}^{2} & =102.2400 \\
(\mathrm{P} & =0.0000)\end{aligned}$ & $\begin{array}{l}\mathrm{Chi}^{2}=5.7400 \\
(\mathrm{P}=0.0165)\end{array}$ & $\mathrm{N} / \mathrm{A}$ & $\mathrm{N} / \mathrm{A}$ \\
\hline
\end{tabular}

* shows significance at 0.01 level; $* *$ shows significance at 0.05 level and ${ }^{* * *}$ shows significance at 0.001 level. Numbers in brackets show standard errors. 
Both Prais-Winston and ARMA estimation is undertaken in the software STATA by maximum likelihood methods. Harvey [14], Hamilton [15] and Gourieroux and Monfort [16] explicate the fuller details of Prais-Winston and ARMA model employed in this study to account for autocorrelation of residual errors. The generalized ARMA model is shown in Equations (4) and (5). Prais-Winston regression model is a special case of ARMA with first order autocorrelation value of $p=1$, while time-differencing (d) and moving average (q) parameters are assumed to be zero. Overall, the estimated Prais-Winston regressions (Models 3 and 7) appear very robust that explain significant amount of variation in the observed data $\left(\mathrm{R}^{2}\right.$ at $87.15 \%$ and $67.91 \%$ respectively for Models 3 and 7 ) while minimizing heteroskedasticity and first-order autocorrelation. The Prais-Winston regression models should therefore be used to interpret the study findings with respect to quantifying the effects of changing hurricane intensities, hurricane frequencies, housing densities and agricultural LULC on inflation adjusted damages (Table 2) and inflation adjusted damages as a proportion of FRTW (Table 3).

$$
\begin{gathered}
\operatorname{Ln}(D)_{t}=\sum_{r=1}{ }^{7} \beta_{r t} X_{r t}+\mu_{t} \\
\mu_{t}=\sum_{\mathrm{i}=1}{ }^{p} \rho_{i} \mu_{t-i}+\sum_{j=1}{ }^{\mathrm{q}} \theta_{j} \varepsilon_{\mathrm{t}-\mathrm{j}}+\varepsilon_{\mathrm{t}}
\end{gathered}
$$

\section{Results and Findings}

\subsection{Predicting Inflation-Adjusted Damages}

Table 2 presents results from 4 regression models that predict inflation adjusted damages (in 2005 US\$ millions) from land-falling hurricanes in the Atlantic and the Gulf coasts of the U.S.: OLS Model 1; Log-linear Model 2; Prais-Winston Model 3 and ARMA ( $p=5, d=1$ and $q=5)$ Model 4. As argued in the previous section, Prais-Winston Model 3 with $\mathrm{R}^{2}$ of $87.15 \%$ appears most robust with no evidence for heteroskedaskticity and first-order auto-correlation. Figure 5 plots the observed log of damages against the Model 3 predicted log of damages. Residuals from Model 3 are also plotted in the third line shown in Figure 5. While not a perfect fit, Model 3 comes pretty close to minimizing mean square error and predicting the observed pattern of damages from hurricanes that made landfall in the southeastern U.S. in the 20th century. Next, findings about the magnitude, direction and significance of the predictors of inflation-adjusted damages derived from Model 3 (and compared with Model 4) are presented.

Model 3 predicts that a one unit increase in the average intensity (on SS scale) of land-falling hurricanes is significantly $(p>0.001)$ correlated with a $130.18 \%$ increase in the log of annualized damages, holding all other variables in the equation constant. Since the observed mean intensity of land-falling hurricanes is 1.71 for the 20 th century, $8 \%$ to $16 \%$ projected increase in the 21 st century under unmitigated climate change scenario translates into average annual intensity between 1.84 and 1.98 on SS scale, which will be approximately equivalent from $10.41 \%(8 \% \times 130.18 \%)$ to $20.82 \%$ $(16 \% \times 130.18 \%)$ expected annual increase in the log of inflation-adjusted damages. Since a $1 \%$ increase in the inflation-adjusted annual damages is approximately equivalent to (2005) US\$29.38 million (from Table 1), a $10.41 \%$ to $20.82 \%$ increase implies approximate increase in annual damages from (2005) US\$305.84 million to US\$611.69 million. 
Figure 5. Observed versus Model 3 predicted log of damages and residual errors.

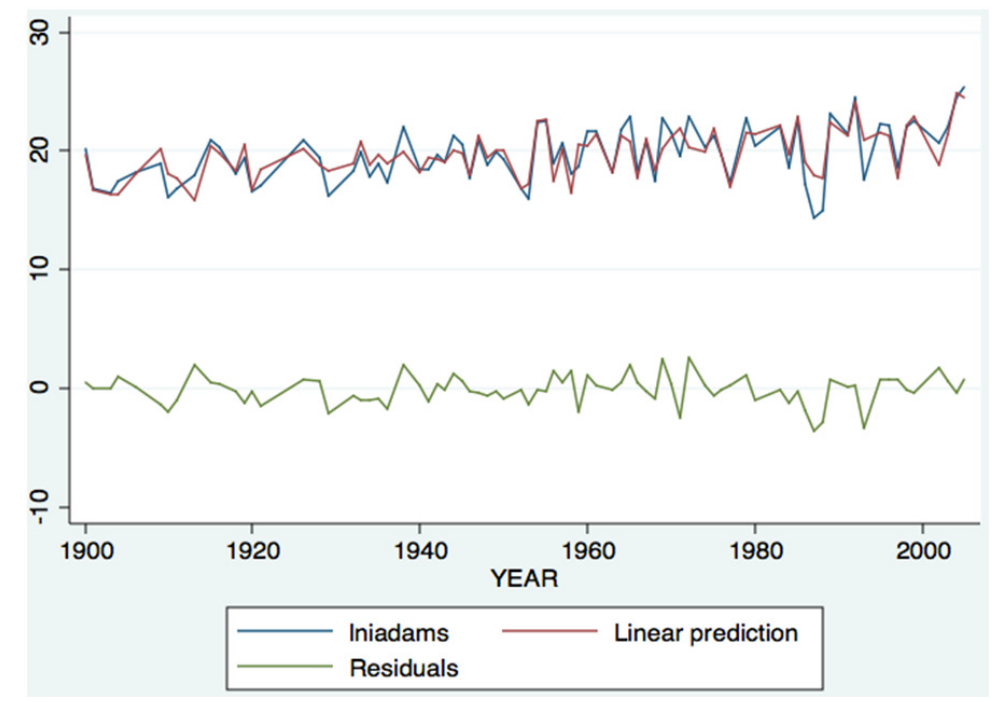

Higher frequency of land-falling hurricanes significantly increases the log of annualized damages. Each additional land-falling hurricane increases damages by $57.62 \%$. The effects of housing density and agricultural cover are also positive and significant in explaining the annualized variation in inflation-adjusted damages. Model 3 predicts that a $1 \%$ increase in the agricultural land cover of the affected lands increases annualized damages by $1.51 \%$. Using the mean values from Table 1 (mean damage $=2937.73$ million), this means that the $1.51 \%$ would translate into approximately (2005) US\$44.35 million. Further, from Table 1, average annual affected area is 13079.13 square miles, $31.07 \%$ of which translates into 4063.68 square miles of average affected agricultural area every year. A $1 \%$ increase in affected agricultural area is thus equivalent to approximately 40.63 square miles, which results in average damage of (2005) US\$44.35 million. Equivalently, each additional square mile of agriculture cover in coastal and inland states thus results in approximate damage of (2005) US\$1.09 million annually. The coefficients on SST Nino and FRTW are not statistically significant, which is rather surprisingly a different result than earlier studies [5,6]. The effects of housing density on inflation-adjusted damages are modeled as a cubic function for Model 3. Average increase of 1 house per square mile of affected area results in $2.68 \%$ higher damages (significant at $1 \%$ level) with a decreasing second order effect of $0.005 \%$ (significant at $5 \%$ level) and an increasing third order effect of $0.000002 \%$ (significant at $5 \%$ level). Since a $1 \%$ increase in the inflation-adjusted annual damages is approximately equivalent to (2005) US\$29.38 million (from Table 1), a 2.68\% increase is approximately equivalent to (2005) US\$78.738 million (ignoring second and third order effects). Overall, the effects of housing density and agricultural land-cover are significantly positive in inducing higher damages from land-falling hurricanes and thus demand serious policy and planning consideration for any meaningful land-use adaptation to climate change in the coastal and adjacent inland states. 


\subsection{Predicting Inflation-Adjusted Damages as a Proportion of FRTW}

As a proportion of FRTW, inflation-adjusted damages range from 0 to $0.99 \%$ during the study period. Table 3 presents four additional regression models that predict normalized inflation-adjusted damages as a proportion of FRTW: OLS Model 5, Loglinear Model 6, Prais-Winston Model 7 and ARMA $(5,1,5)$ Model 8. Independent variables for these four models are the same as previous four models, except that FRTW was removed due to its usage as a normalizer of the dependent variable. Prais-Winston Model 7 with $\mathrm{R}^{2}$ of $67.91 \%$ appears most robust with no evidence for heteroskedaskticity and first-order auto-correlation. Figure 6 plots the observed log of damages per FRTW against the Model 3 predicted log of damages per FRTW. Residuals from Model 3 are also plotted in the third line shown in Figure 6. ARIMA $(5,1,5)$ model 8 shows considerable non-stationarity in the dependent variable due to significant higher order autocorrelations and moving averages. Relatively higher variation in the residuals shown in Figure 6 mirrors this non-stationarity. Despite this non-stationarity of residuals, both Prais-Winston Model 7 and ARIMA $(5,1,5)$ model 8 predictors appear to have similar direction, magnitude and significance.

Figure 6. Observed versus Model 7 predicted log of damages as a \% proportion of FRTW and residual errors.

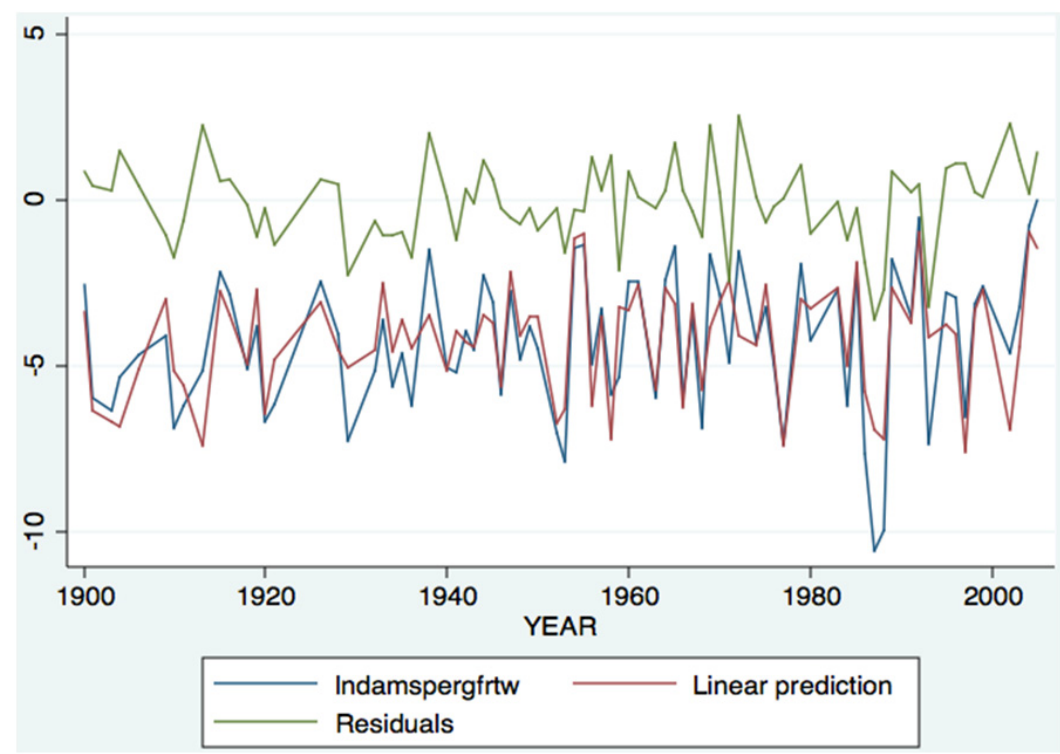

One unit increase in average annual hurricane intensity (on SS scale) is predicted to lead to $130.65 \%$ increase in damages as a proportion of FRTW, which has a mean value of $0.05 \%$ during the 20th century. Each additional house per square mile leads to $2.61 \%$ increase in damager per FRTW with a decreasing second order effect of $0.005 \%$ and increasing third order effect of $0.000002 \%$. Each additional hurricane causes $59.09 \%$ increase in damages as a proportion of FRTW. Further, each additional $\%$ of agricultural land in the affected area leads to $1.36 \%$ higher damage as a proportion of FRTW. Overall, the direction, magnitude and significance of predictors for damages as a proportion of FRTW (i.e., Table 3) are consistent with the predictors for inflation-adjusted damages (i.e., Table 2). 


\section{Limitations and Prospects of the Dynamic Time-Series Modeling Approach}

In classical general equilibrium models, extreme weather events were treated as exogenous shocks/events [17]. Global climate change science has changed this perspective: extreme weather events need to be modeled as endogenous events in truly accurate dynamic models both due to long term climate change mitigation and adaptation effects. In theory, some Vulnerability Analysis Models, Risk Management Models and Integrated Assessment Models could be designed to endogenize the socio-economic impacts of global climate change on hurricane damages. Empirical estimation of such comprehensive models that endogenize the effects of global climate change is faced with some critical limitations, which include scale selection and boundary issues, model specification problems, weighting issues, and significant loopholes in measuring empirical data. As opposed to a comprehensive model, this paper has presented a reduced form dynamic model that requires minimal data to predict annualized damages from changing hurricane intensities under shifting socio-economic and land-use conditions over time. While reduced form models are easy for integrating theory with data, scalable, well established in forecasting science and can perhaps also provide external validity test for comprehensive models, such models also suffer from some serious limitations and the results of this study must be interpreted in the light of these limitations. First of all, these models are highly aggregated. While future versions of such models could be built as multi-level models (assuming damage data is available at sub-levels, e.g., states, counties, cities etc.), the reduced form models by definition ignore structural effects that are included in comprehensive models such as integrated assessments and vulnerability assessments. The reduced form models thus cannot replace comprehensive models, rather they complement the knowledge base for developing full structural models. Finally, reduced form models cannot account for novelty and surprises, which is also known as the classical problem of historicity in forecasting science.

\section{Implications for Land-Use Adaptation to Climate Change}

This study has quantified the effects of changing housing densities and agricultural land cover on inflation-adjusted damages from land-falling hurricanes in the Atlantic and Gulf coastal (and adjacent inland) states of the U.S. From the larger climate policy design perspective, these estimates could be used to calculate marginal effects of climate change induced increases in the intensity of hurricanes. For example, 8 to $16 \%$ increase in the average intensity of hurricanes will very likely lead to increased annual damages from (2005) US\$305.84 million to US\$611.69 million, holding constant other effects. If global circulation models are revised in future that predict a revised estimate of changes in hurricane intensities and frequencies induced by anthropogenic global climate change, such dynamic time-series modeling approaches could be used to parse out revised damage estimates. Obviously, these estimates are based upon the assumption of "spontaneous" adaptation to climate change. In contrast, the findings from this and other related studies [8] could also potentially be used by planners and policy makers in the U.S. and other hurricane and typhoon risk-prone countries to design and implement a "planned" adaptation. While coastal and other adjacent inland communities face higher risk from global climate change induced events (e.g., sea level rise, flash floods and so forth) and a cumulative disaster risk management approach might be more appropriate, it is clear from the findings of this study that medium to long term land-use adaptation must be an integral component of this cumulative "planned" 
adaptation. While the evidence from this study implies that a medium to long term land use adaptation in the form of capping housing density and agricultural cover in the coastal (and adjacent inland) states can significantly reduce economic damages from intense hurricanes, future studies must compare the benefits of such land use adaptation policies against the costs of development controls implied in housing density caps and agricultural land cover reductions.

\section{Conclusions}

Reduced form models can be used to quantify land use adaptation benefits (i.e., avoided damages) as compared to the baseline case of no planned/spontaneous adaptation. This study quantifies the adaptation effects of potentially policy driven caps on housing densities and agricultural cover in coastal (and adjacent inland) areas vulnerable to hurricane damages in the Atlantic and Gulf Coastal regions of the U.S. Time series regressions, especially Prais-Winston and Autoregressive Moving Average (ARMA) models, are estimated to forecast the economic impacts of hurricanes of varying intensity, given that various patterns of land use-housing, agriculture-emerge in the Atlantic and Gulf coastal states of the U.S. The Prais-Winston and ARMA models use observed time series data from 1900 to 2005 for inflation adjusted hurricane damages and socio-economic and land-use data in the coastal or inland regions where hurricanes caused those damages. The results from this study provide evidence that increases in housing density and agricultural cover cause significant rise in the de-trended inflation-adjusted damages as well as damages as a proportion of FRTW. As expected, higher intensity hurricanes significantly increase the economic damages. The evidence from this study implies that a medium to long term land use adaptation in the form of capping housing density and agricultural cover in the coastal states can significantly reduce economic damages from intense hurricanes. In future research, the effects of specific land-use policy interventions, such as land-use taxes, subsidies and re-insurance schemes, may be evaluated to estimate benefit-cost ratios of alternate policy interventions that simultaneously minimize economic damages from more intense hurricanes under unmitigated global climate change scenarios and maximize societal benefits derived from LULC of housing and agricultural activities.

\section{Acknowledgments}

Work on this paper and research supporting it is funded by the National Science Foundation grants 0433165 and EPS-1101317. Thanks to Chris Landsea for providing hurricane damages data and Jennifer Boenhart for helping with GIS Census data.

\section{Conflict of Interest}

The author declares no conflict of interest. 


\section{References and Notes}

1. IPCC. Climate Change 2007: Synthesis Report. In Intergovernmental Panel on Climate Change, Fourth Assessment Report, Summary for Policymakers; Cambridge University Press: Cambridge, UK, 2007.

2. Knutson, T.R.; Tuleya, R.E. Impact of co2-induced warming on simulated hurricane intensity and precipitation: Sensitivity to the choice of climate model and convective parameterization. J. Clim. 2004, 17, 3477-3495.

3. Pielke, R.A., Jr. Are there trends in hurricane destruction? Nature 2005, 438, E11.

4. Emanuel, K. Increasing destructiveness of tropical cyclones over the past 30 years. Nature 2005, 436, 686-688.

5. Pielke, R.A., Jr.; Landsea, C.N. Normalized hurricane damages in the United States. Weather Forecast. 1998, 13, 621-631.

6. Pielke, R.A., Jr.; Landsea, C.N. La nina, el nino, and atlantic hurricane damages in the united states. Bull. Am. Meteorol. Soc. 1999, 80, 2027-2033.

7. FRTW is Fixed Reproducible Tangible Wealth reported by Bureau of Economic Analysis in the U.S. FRTW is generally highly correlated with Gross Domestic Product (GDP) of a country and is considered a standardized measure of wealth.

8. IPCC. 2012: Managing the Risks of Extreme Events and Disasters to Advance Climate Change Adaptation. In A Special Report of Working Groups I and II of the Intergovernmental Panel on Climate Change; Field, C.B., Barros, V., Stocker, T.F., Qin, D., Dokken, D.J., Ebi, K.L., Mastrandrea, M.D., Mach, K.J., Plattner, G.-K., Allen, S.K., Tignor, M., Midgley, P.M., Eds.; Cambridge University Press: Cambridge, UK; New York, NY, USA, 2012

9. Kelly, P.M.; Adger, W.N. Theory and practice in assessing vulnerability to climate change and facilitating adaptation. Clim. Chang. 2000, 47, 325-352.

10. Adger, W.N.; Arnell, N.W.; Tompkins, E.L. Successful adaptation to climate change across scales. Glob. Environ. Chang. 2005, 15, 77-86.

11. National Hurricane Center (NHC) and Property Claims Inc. provided hurricane damages data.

12. Katz, R.W. Stochastic modeling of hurricane damage. J. Appl. Meteorol. 2002, 41, 754-762.

13. $1 \%$ significant value for lower bound of d-statistic with $\mathrm{N}=80$ and $\mathrm{k}=10$ is 1.232 , which is higher than the estimated value of 1.0324 for Model 1.

14. Harvey, A.C. Forecasting, Structural Time Series Models and the Kalman Filter; Cambridge University Press: Cambridge, UK, 1989.

15. Hamilton, J.D. Time Series Analysis; Princeton University Press: Princeton, NJ, USA, 1994.

16. Gourieroux, C.; Monfort, A. Time Series and Dynamic Models; Cambridge University Press: Cambridge, UK, 1997.

17. Nordhaus, W.; Yang, Z. A regional dynamic general-equilibrium model of alternative climate-change strategies. Am. Econ. Rev. 1996, 86, 741-765.

(C) 2012 by the authors; licensee MDPI, Basel, Switzerland. This article is an open access article distributed under the terms and conditions of the Creative Commons Attribution license (http://creativecommons.org/licenses/by/3.0/). 